\title{
Spiritual Leadership: Practical Implementation for School Principals in Indonesia*
}

\author{
Indra Dwi Prasetyo \\ Faculty of Education, Monash University, Melbourne, Australia
}

\author{
How to cite this paper: Indra Dwi Prasetyo. \\ (2019). Spiritual Leadership: Practical \\ Implementation for School Principals in \\ Indonesia*. The Educational Review, USA, \\ 3(3), 28-33. \\ http://dx.doi.org/10.26855/er.2019.03.001
}

*Corresponding author: Indra Dwi Prasetyo, Faculty of Education, Monash University, Melbourne, Australia.

Email: dwiprasetyoindra@gmail.com

\begin{abstract}
This study investigated the impact of Spiritual Leadership(SL) for school principals in Indonesia, both of the positives as well as its drawbacks. Although several researches have scrutinized the use of SL, those studies do not emphasis the relevance of SL in Indonesia, specifically in education context. Therefore, this research attempts to reflect SL implementation in Indonesia which has the ideology of "Belief in Oneness God" as the first principle among other four principle of Pancasila (The Five Principles). Through the exploration of existing empirical studies, this investigation classifies three opportunities of implementing SL, including improving teachers' performances, enhancing teachers' commitment and creating inclusive environment. Besides, some challenges that potentially exist is also described. Both side of opportunities and drawbacks can be considered in implementing SL in the future school environments.
\end{abstract}

\author{
Keywords \\ Spiritual Leadership, leadership, School Principal
}

\section{Introduction}

Indonesia is an archipelago country which consists of 17.504 islands stretching from the East to the West (Badan Pusat Statistik, 2017). Consequently, there are numbers of people who live and create their society based on geographical and ethnic aspects. Based on the 2010 population census for Indonesia, there are 1331 ethnic classifications in the raw data, and turn into 600 major ethnic groups after being re-classified (Ananta, Arifin, Hasbullah, Handayani, \& Pramono, 2015). Those ethnic groups are relatively fractionalized - even though not as polarised - and forming cultural varieties among society (Arifin, Ananta, Utami, Handayani, \& Pramono, 2015). Based on the information above, multiculturalism among the community in Indonesia is inevitable.

Multiculturalism is not a rigid aspect that could only be seen through one single point of view, but also provides another dimension. One of the dimensions existing in multiculturalism is multicultural in education. The success of multicultural in schooling is detectable when the students understand, recognise and respect a reality of differences in a diverse ethnic to obtain excellent learning for the students(Banks, 2013; McCormick, 1984; Raihani, 2012). In order to achieve this objective, the cooperation between school components and the students is essentially needed, and one crucial element is school principal's leadership.

In recent years, the discussion of leadership is emerging among researchers, and one leadership style discussed is Spiritual Leadership (SL). In this essay, the author will critically evaluate the benefit of implementing SL for the school principals in Indonesia, specifically, in a multicultural context. In particular, this paper will investigate the nature of SL and the way it contributes to school principals positively while considering the possible challenges that might appear. Hence, the writer would like to argue that SL is beneficial to be implemented by the school principals in Indonesia. This essay begins by defining SL and elaborating the background of the issue investigated before analysing the benefits. The possible challenges regarding the implementation will also be provided before summarising the investigation and outlining some recommendations for further application of SL.

SL is an outgrowth of leadership theory which emphasises how leaders influence and motivate their followers (Fry \& Slocum, 2008). Nevertheless, what makes it different with other leadership theory is the domain of SL which is not only focused on varying degrees of one or more aspects of physical, mental or emotional but also spiritual (Fry, 2003). Theoretically, SL is defined as a set of values, attitudes and behaviours that are needed to intrinsically motivate and influence one's self or others to work as a calling, to create better organizational outcomes (Fairholm \& Gronau, 2015; Fry, 2003; Krishnakumar, 
Houghton, Neck, \& Ellison, 2015). The terms of 'spirituality' in this investigation is not derived from formal religion as they have different constructswhere formal religion associates with outward expression and spiritual deals with inward experiences (Marques, Dhiman, \& King, 2005). Consequently, leadership spirituality in this investigation is embedded to all human-with or without formal religion(Christopher \& John, 1994).

Several studies (see Afsar, Badir, \& Kiani, 2016; Chawla \& Guda, 2010; Chegini \& Nezhad, 2012) claim that SL provides positive impacts in the organisation regarding the sense of belonging, job satisfaction as well as commitment. Though, critical investigation of SL in the educational sector is considered limited. Some of them are focused on SL implementation in corporation, industrial area or more general organisation. Therefore, to elaborate between SL and school altogether throughout this essay, the conception of school will equally refer to the concept of an organisational structure which has a leader and employees (Trasca, 2014). In more practical, the leader in school is the principal whose task is to ensure that the school organisational elements - teachers and students - functioned efficiently (Leithwood \& Montgomery, 1982).In addition, Indonesian principal is selected as a frame in this essay because Indonesia is a religious country which "Belief in Oneness God" is stated in the first of Five Principle of Indonesia, Pancasila (Hefner, 2013), consequently, holding one religion is an obligation for all Indonesian people. Reflecting the circumstances mentioned above, implementing SL for school principal in Indonesia is considered relevant.

Based on the explanation mentioned above, this paper aims to answer these research questions including (1) what are the possible benefits of implemting SL for school principals in Indonesia and (2) what are the potential shortcoming regadring SL implemtation? While the discussion in the paper can be a reference to enrich the knowledge in SL area in education fields, it can also help the principles and the teachers to implement SL in their school environment.

\section{Research Method}

This investigation is considered as a conceptual paper which utilises secondary data analysis. Bryman (2016) contends that secondary data analysis is the data which are gathered by someone else. In this specific research, an in-depth literature review of the areas of SL was collected to analyse the current work of SL and its application in Indonesian context.

There are several research stages managed to complete this paper. Initially, the author conceptualises a set of research questions which related on how SL contribute positively as well its potential shortcomings in Indonesian classroom context. Secondly, the author explores, identities and examines the available dataset in the field of SL and its implication in education fields. Lastly, the author provides the identification and evaluation result of the dataset to answer the research question previously mentioned and give some possible recommendations for relevant practice in the future.

\section{Discussion}

\section{Spiritual Leadership in Practice}

\subsection{Improving Employee Performance}

SL can positively affect employee performance in several ways. First and foremost, SL can lead individuals to experience an awareness at the more in-depth level, thereby increasing their intuitive abilities (Christopher \& John, 1994). Deep intuition, in turn, is considered as essential to help teachers in decision making to handle and evaluate different situations and performance on students (Johansson \& Kroksmark, 2004; Resnik, 2017). This skill is needed by the teachers to identify their students, therefore, suitable learning strategies can be implemented relevantly based on the students' conditions. Besides, teachers' creativity in teaching will also increase based on the depth of intuition they have since both attributes are interrelated each other(Karwowski, 2008). Creativity in education is beneficial for the teachers since it helps them to reduce the level of boredom in the classroom through a wide range of teaching methods and learning materials (Naser, 2016). It also contributes to the development of creativity among the students (Naser, 2016). Therefore, through SL implementation, the teachers can create a workplace environment where they can deepen their intuition to achieve a successful learning experience.

In addition, the employees whose SL is implemented by their leader in their workplace tend to be more indulgedin their job. They who are spiritually fulfilled will consider work as a calling with no burden as well as meaningful (Krishnakumar et al., 2015), thus, create a happier environment at the workplace (Kaya, 2015). The more comfortablebackground they have, the more the sense of enjoyment they will get resulting inproductive members who work optimally (Kaya, 2015). When it is framedin a school context, the teachers who teach happily will stimulate their students to be more reactive as well creative (Scoffham \& Barnes, 2011). Another study conducted by Bullough Jr (2011) explains that happiness expressed by the teachers while teaching will help the students to reach their successful learning, particularly in solving their learning problem. As a result, implementing SL in a school will not only influence the teachers to be happier in teaching experience but also help the students to the betterment of learning.

Having said this, the implementation of SL by the principal will influence the teachers to be more productive in work. Through the application of SL in school by the principal, the teachers are more intuitive in the classroomin terms of decision making and 
class management. Consequently, they are more intuitively creative in choosing and designing learning materials based on the students' need, therefore, the boredom occur in the classroom will be minimalised. Moreover, a spiritual workplace will affect teachers' motivation in teaching to be more indulged and happier. This condition will formulate an enjoyable learning condition where the students may find it helpful to overcome their learning difficulties.

\subsection{Strengthening Professional Commitment}

Besides the benefits explained above, implementing SL in school will also enhance job commitment among workers. Job commitment is defined as a circumstance when workplace goals and individuals within are congruent and integrated (Riasudeen \& Srinivasan, 2011). In this context, SL provides the environment where the workers are highly committed todoing their job since they have similar spiritual calling and membership among them (Fry, 2003). Furthermore, the religious workplace will build a transcendent interconnectedness in the workplace and sense of belonging in the inner life of each worker, hence, their commitment to work is enhanced (Chawla \& Guda, 2010). A study on professional workers conducted by Chawla and Guda (2010) also shows that expressing SL in a workplace makes the workers work optimally, increase their commitments towards the job they are doing and reduce their intention to leave. In a school context, job commitment is essential for the teachers since it creates a positive and supportive organisational climate (Bogler \& Nir, 2014; Collie, Shapka, \& Perry, 2011)and maintains agood relationship with their principals (Price, 2011). Consequently, their self-esteem and teaching quality will be enhanced, influenced by their commitments in work (Cerit, 2009).

Another concern related to professional commitment is job satisfaction as the result of SL implementation. Job satisfaction is related to how the workers see their work meaningful in terms of physical, mental and spiritual (Krishnakumar et al., 2015; Su-Chao \& Ming-Shing, 2007). In a spiritual workplace, the workers may find religious experiences in their work (Grant, O'Neil, \& Stephens, 2004) and develop their spiritual well-being which may lead to physical well-being and better health (Fry, Matherly, \& Vitucci, 2006). If it is contextualised to the teachers' point of view, SL has a paramount role in motivating them to teach more productively since it plays within their intrinsic domain, thus, will enhance their job satisfaction (Cerit, 2009; Fry, 2003). Moreover, teachers' job satisfaction will directly influence the performance of the students in terms of their social, emotional and educational success(Cerit, 2009). Because of the pleasureachieved by the teachers in school, those who have a high-level work satisfaction may not intend to leave the job or organisation(Chawla \& Guda, 2010), in another word, strengthening their professional commitment.

In conclusion, another benefit of implementing SL in school is identified on how teachers strengthen their professional commitment. Firstly, given the condition where the school is spiritually fulfilled, the teachers may find a strong sense of belonging to others. It will reduce their willingness to leave their job or organisation. Another concern related to this is how the SL implementation provides job satisfaction to the teachers. This phenomenon will not only create a thriving learning environment for the students but also offer a professional commitment among the teachers.

\subsection{Supportive Inclusive Organisation}

Another advantage of implementing SL in the Indonesian schools is to promote an inclusive organisation. Inclusion in the organisation can be explained as the way an organisation acts to respond the different composition of groups happened in a workplace in order to create a better work environment (Roberson, 2006). The spiritual leader will display respectful behaviour such as empathy, accepting different voices, open communication to the individuals with diverse cultures and spiritual preferences(George \& Katerina, 2017). It happens because SL is derived from universal values of altruistic love that are extracted to leadership practices (George \& Katerina, 2017). This concept of inclusion is suitable with the condition of Indonesia which has 600 ethnic groups with a variety of religions and beliefs (Ananta et al., 2015). In the school context, this feature of SL will create a mutual understanding when the students and the teachers acknowledge and respect each other in terms of culture and belief (Gay, 2002b). Moreover, a study shows that teachers with inclusive behaviour tend to develop their pedagogy experience in their classroom (Jabbar \& Hardaker, 2013), thus, helping their students to achieve their better learning goal.

For further implementation, inclusive environment where SL is applied may lead to an organisational transformation. As inclusive environment need a different paradigm in seeing differences, it can stimulate an organisational transformation where the organisation change its environment, vision and organisational cultures (Fry, Vitucci, \& Cedillo, 2005). An investigation conducted by Fry and Cohen (2009) proves that SL helps the leaders to transform their leadership theory and organisational practices based on various spiritual beliefs within the organisation. This notion is consideredessential in the schoolcontext since the principals need to be responsive in seeing the differences among the teachers and the students to make the school viable and adjustable to the competition (Trasca, 2014). Hence, inclusive spiritual workplace supports the principals to create a betterment school which is responsive to the differences.

To summarise, SL implementation in school is beneficial for principals because it provides an inclusive circumstance for the organisation. It can be achieved through respecting another spiritual belief existing in the school. By doing so, mutual understanding will be built among teachers and students, consequently, teaching experience among them will be enhanced. Moreover, being inclusive will also lead to an organisational transformation where the school become more responsive to understand the differences to cope with global competition. 


\section{4. Challenges Towards Spiritual Leadership}

Besides the benefits outlined above, it cannot be neglected that challenges towards SL implementation may also appear. As the trust built by the employees is strong to their leader, the exploitation of the leader may occur (Krishnakumar et al., 2015). This will be experienced in the settings when the leader has an ultra legitimacy, then, exploitthe teachers. The example of this notion in the school is when the principal force the teachers to teach over the limit, such as extended work-hour (Fry \& Cohen, 2009). This circumstance will decrease teachers' performance and fall it behind expectation (Krishnakumar et al., 2015). Furthermore, this practice will block teacher's creativity as they are too afraid to explore and too stick to the rules made by the principals. At the end, the essence of leadership will transform to cult, and narrowed to a single-power relation, from principal to the teachers. Another obstacle is an exclusive environment where the school only acknowledge one belief (Krishnakumar et al., 2015). Therefore, the individuals within cannot express their diverse beliefs. For instance, the matter of minority and majority of religion in one school will cause a different behaviour from the principal as well as the teacher towards their staff or students. If this happens to the school context, the discrimination may be experienced by the students, moreover, it will affect their learning outcomes (Fives \& Gill, 2014; Gay, 2002a).

\section{Conclusion and Recommendation}

In summary, it is acceptable that SL is beneficial to be implemented in Indonesia, mainly on how the principals influence their working environment through the teachers and the students. Firstly, having investigated this issue, this essay shows that implementing SL will help principals to improve teachers' performances. It happens because SL provides an opportunity to deepen teachers' intuition to create a happier working environment. Thus, their performance will increase and influence their students' learning outcome. Further, implementing SL will also strengthen teachers' commitment since the teachers have similar spiritual calling and membership one another. In addition, the conducive workplace will promote job satisfaction among the teachers, therefore, their intention to leave their job will be reduced. Another aspect influenced by SL implementation in school is an inclusive environment in the workplace. This situation formed because SL can accept different beliefs in the workplace, so the equality among teachers is concerned. Moreover, this inclusive environment will initiate an organisational transformation where the schoolis being adaptive and responsive to various kind of differences in terms of individuals' culture and belief.

In spite of having several benefits as mentioned above, it is inevitable that possible challenges on SL implementation may also emerge. Principals' exploitation of teachers and teachers' discrimination towards students belief are two main obstacles which need to be taken into account. For such reasons, it is suggested to conduct another investigation to overcomethose issues. Moreover, in order toachieve the goal of SL more comprehensively, it is suggested that the participation is not only focused to the principals, but also the whole community in school. It is essential to see how both of the teachers and the students can work collaboratively to create a better spiritual workplace on their own roles.

\section{References}

Afsar, B., Badir, Y., \& Kiani, U. S. (2016). Linking spiritual leadership and employee pro-environmental behavior: The influence of workplace spirituality, intrinsic motivation, and environmental passion. Journal of Environmental Psychology, 45, 79-88. doi:10.1016/j.jenvp.2015.11.011

Ananta, A., Arifin, E. N., Hasbullah, M. S., Handayani, N. B., \& Pramono, A. (2015). Demography of Indonesia's ethnicity: ISEAS - Yusof Ishak Institute.

Arifin, E. N., Ananta, A., Utami, D. R. W. W., Handayani, B. N., \& Pramono, A. (2015). Quantifying Indonesia's ethnic diversity. Asian Population Studies, 11(3), 233-256. doi:10.1080/17441730.2015.1090692

Banks, J. A. (2013). The construction and historical development of multicultural education, 1962-2012. Theory Into Practice, 52(sup1), 73-82. doi:10.1080/00405841.2013.795444

Bogler, R., \& Nir, A. E. (2014). The contribution of perceived fit between job demands and abilities to teachers' commitment and job satisfaction. Educational Management Administration \& Leadership, 43(4), 541-560. doi:10.1177/1741143214535736

Bryman, A. a. (2016). Social research methods (Fifth edition. ed.): New York, NY : Oxford University Press.

Bullough Jr, R. V. (2011). Hope, happiness, teaching, and learning. In New Understandings of Teacher's Work (pp. 15-30): Springer.

Cerit, Y. (2009). The effects of servant leadership behaviours of school principals on teachers' job satisfaction. Educational Management Administration \& Leadership, 37(5), 600-623. doi:10.1177/1741143209339650

Chawla, V., \& Guda, S. (2010). Individual spirituality at work and its relationship with job satisfaction, propensity to leave and job commitment: An exploratory study among sales professionals. Journal of Human Values, 16(2), 157-167. 
Chegini, M. G., \& Nezhad, Z. F. (2012). The effect of spiritual leadership and other elements on employees' empowerment of Iran's bank: Case study of Guilan Province. African Journal of Business Management, 6(28), 8420-8434. doi: 10.5897/ AJBM11.2036

Christopher, P. N., \& John, F. M. (1994). Thought self-leadership: Finding spiritual fulfilment in organizational life. Journal of Managerial Psychology, 9(6), 9-16. doi:10.1108/02683949410070151

Collie, R. J., Shapka, J. D., \& Perry, N. E. (2011). Predicting teacher commitment: The impact of school climate and socialemotional learning. Psychology in the Schools, 48(10), 1034-1048. doi:10.1002/pits.20611

Fairholm, M. R., \& Gronau, T. W. (2015). Spiritual leadership in the work of public administrators. Journal of Management, Spirituality \& Religion, 12(4), 354-373. doi:10.1080/14766086.2015.1060516

Fives, H., \& Gill, M. G. (2014). International handbook of research on teachers'beliefs: Routledge.

Fry, L. W. (2003). Toward a theory of spiritual leadership. The Leadership Quarterly, 14(6), 693-727. doi:10.1016/ j.leaqua.2003.09.001

Fry, L. W., \& Cohen, M. P. (2009). Spiritual Leadership as a Paradigm for Organizational Transformation and Recovery from Extended Work Hours Cultures. Journal of Business Ethics, 84, 265-278.

Fry, L. W., Matherly, L. L., \& Vitucci, S. (2006). Spiritual leadership theory as a source for future theory, research, and recovery from workaholism. Research companion to working time and work addiction, 330.

Fry, L. W., \& Slocum, J. W. (2008). Maximizing the Triple Bottom Line through Spiritual Leadership. Organizational Dynamics, 37(1), 86-96. doi:10.1016/j.orgdyn.2007.11.004

Fry, L. W., Vitucci, S., \& Cedillo, M. (2005). Spiritual leadership and army transformation: Theory, measurement, and establishing a baseline. The Leadership Quarterly, 16(5), 835-862. doi: 10.1016/ j.leaqua.2005.07.012

Gay, G. (2002a). Culturally responsive teaching in special education for ethnically diverse students: Setting the stage. International Journal of Qualitative Studies in Education, 15(6), 613-629. doi:10.1080/0951839022000014349

Gay, G. (2002b). Preparing for Culturally Responsive Teaching. Journal of Teacher Education, 53(2), $106-116$. doi:10.1177/0022487102053002003

George, G., \& Katerina, G. (2017). The role of spiritual leadership in fostering inclusive workplaces. Personnel Review, 46(5), 908-935. doi:10.1108/PR-11-2015-0286

Grant, D., O'Neil, K., \& Stephens, L. (2004). Spirituality in the Workplace: New Empirical Directions in the Study of the Sacred. Sociology of Religion, 65(3), 265-283. doi:10.2307/3712252

Hefner, R. W. (2013). The study of religious in Indonesia The Review of Faith \& International Affairs, 11(2), 18-27. doi:10.108 0/15570274.2013.808038

Jabbar, A., \& Hardaker, G. (2013). The role of culturally responsive teaching for supporting ethnic diversity in British University Business Schools. Teaching in Higher Education, 18(3), 272-284. doi:10.1080/13562517.2012.725221

Johansson, T., \& Kroksmark, T. (2004). Teachers' intuition-in-action: How teachers experience action. Reflective Practice, 5(3), 357-381. doi:10.1080/1462394042000270673

Karwowski, M. (2008). Giftedness and Intuition. Gifted and Talented International, 23(1), 115-124.

Kaya, A. (2015). The relationship between spiritual leadership and organizational citizenship behaviors: A research on school principals' behaviors Kuram ve Uygulamada Egitim Bilimleri, 15(3), 597-606.

Krishnakumar, S., Houghton, J. D., Neck, C. P., \& Ellison, C. N. (2015). The "good" and the "bad" of spiritual leadership. Journal of Management, Spirituality \& Religion, 12(1), 17-37. doi:10.1080/14766086.2014.886518

Leithwood, K. A., \& Montgomery, D. J. (1982). The Role of the Elementary School Principal in Program Improvement. Review of Educational Research, 52(3), 309-339. doi:10.3102/00346543052003309

Marques, J., Dhiman, S., \& King, R. (2005). Spirituality in the workplace: Developing an integral model and a comprehensive definition. The Journal of American Academy of Business, 7(1), 81-91.

McCormick, T. E. (1984). Multiculturalism: Some principles and issues. Theory Into Practice, 23(2), 93-97. doi:10.1080/00405848409543097

Naser, R. A. (2016). Level of Creative Behavior among Teachers of Public Schools within the Green Line from Their Perspective. Journal of Education and Practice, 7(18), 109-119.

Price, H. E. (2011). Principal-teacher interactions. Educational Administration Quarterly, 48(1), 39-85. doi:10.1177/0013161X11417126

Raihani. (2012). Report on multicultural education in pesantren. Compare: A Journal of Comparative and International Education, 42(4), 585-605. doi:10.1080/03057925.2012.672255 
Resnik, D. B. (2017). The Role of Intuition in Risk/Benefit Decision-Making in Human Subjects Research. Accountability in Research, 24(1), 1-29. doi:10.1080/08989621.2016.1198978

Riasudeen, S., \& Srinivasan, P. T. (2011). Predictors of Organisational and Job Commitment in Diverse Organisation. Asia Pacific Business Review, 7(3), 188-197. doi:10.1177/097324701100700317

Roberson, Q. M. (2006). Disentangling the Meanings of Diversity and Inclusion in Organizations. Group \& Organization Management, 31(2), 212-236.

Scoffham, S., \& Barnes, J. (2011). Happiness Matters: Towards a Pedagogy of Happiness and Well-Being. Curriculum Journal, 22(4), 535-548.

Su-Chao, C., \& Ming-Shing, L. (2007). A study on relationship among leadership, organizational culture, the operation of learning organization and employees' job satisfaction. The Learning Organization, 14(2), 155-185. doi:10.1108/09696470710727014

Trasca, I.-M. (2014). Elements of school organization management. Euromentor Journal, 5(2), 52-63. 